\title{
nordon
}

\section{Growth, welfare and values}

Programme for the Danish Presidency of the Nordic Council of Ministers 2015
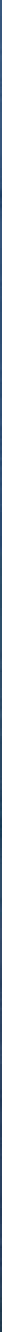


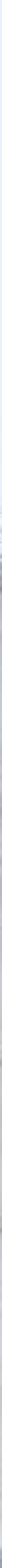

in

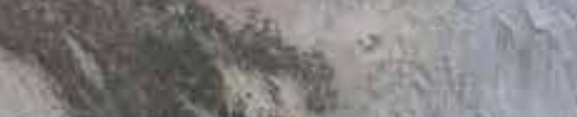

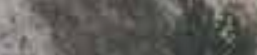

$b^{2} \times x^{2}$

$-\frac{3 x}{6} 8 \%$

\%:
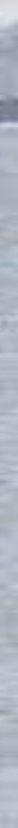

Growth, welfare and values

Programme for the Danish Presidency of

the Nordic Council of Ministers 2015

ISBN 978-92-893-3786-1 (PRINT)

ISBN 978-92-893-3807-3 (PDF)

http://dx.doi.org/10.6027/ANP2014-747

Lillgrund offshore wind farm

ANP 2014:747

Øresund, Denmark/Sweden

(C) Nordic Council of Ministers 2014

Layout: Jette Koefoed

Cover photo: Offshore wind farm in the Sound, Adrian Joachim

Photo: p. 2-3 Jette Koefoed; p. 7 (left) Agnete Schlichtkrull, (right) Claus Bjørn Larsen;

p.12, 15, 19 SignElements; p.10 visitaland.com; p.19, 26-27 ImageSelect;

p. 8, 25 Karin Beate Nøsterud

Print: Rosendahls-Schultz Grafisk

Copies: 1,500

Typeface: Meta LF

Paper: Munken Polar

Printed in Denmark

www.norden.org/en/publications

\section{Nordic co-operation}

Nordic co-operation is one of the world's most extensive

forms of regional collaboration, involving Denmark, Finland,

Iceland, Norway, Sweden, and the Faroe Islands, Greenland, and Åland.

Nordic co-operation has firm traditions in politics, the economy, and culture. It plays an important role in European and international collaboration, and aims at creating a strong Nordic community in a strong Europe.

Nordic co-operation seeks to safeguard Nordic and regional interests and principles in the global community. Common Nordic values help the region solidify its position as one of the world's most innovative and competitive.

\section{Nordic Council of Ministers}

Ved Stranden 18

DK-1061 Copenhagen K

Phone (+45) 33960200 


\section{Growth, welfare and values}

Programme for the Danish Presidency of

the Nordic Council of Ministers 2015

6 Foreword

9 Introduction

11 Growth

14 Welfare

18 Values - international branding of the Nordic Region

22 The Blue Arctic 


\section{Foreword}

In 2015, it will be Denmark's turn to hold the Presidency of the Nordic Council of Ministers and lead the way in this important form of collaboration, which for many decades has served to nurture and enhance the strong sense of affinity between our nations.

The people of the Nordic Region have close ties as a result of their shared history and values, on the basis of which a partnership has evolved that serves as a rich source of mutual inspiration and support. It has also given rise to ways of working together that provide relevant and topical answers to the challenges that we all face.

One example of this is the long-standing commitment to promoting crossborder freedom of movement between our countries, which is crucial if Nordic companies and ordinary people are to reap the benefits of our geographical proximity, shared attitudes and sense of cultural affinity. This will continue to be a key component of Nordic co-operation.

Nordic co-operation has celebrated many successes over the years, but we mustn't rest on our laurels. It is crucial that we continue to generate real added value and come up with tangible solutions to new challenges as they arise.

This is particularly important as we start to recover from the global economic crisis, which had a major impact on our countries. The crisis forced us to make a series of difficult decisions - not least in order to protect the Nordic welfare systems. The latter may well have proved robust but have not emerged unscathed. 
In the next few years, it will be of paramount importance that that we put the crisis behind us for good and cement the foundations of a society that will remain dynamic and innovative. We need to keep creating opportunities for those able to take advantage of them, and provide a safety net for those who find it difficult to cope on their own.

The Danish Presidency will concentrate on four themes designed to strengthen and focus the Nordic partnership. We will turn the spotlight on growth and employment; we will uphold Nordic welfare; we will enhance knowledge of Nordic values by bolstering the Nordic "brand"; and we will focus on the Arctic.

We look forward to a close and rewarding partnership with our Nordic neighbours and friends throughout 2015.
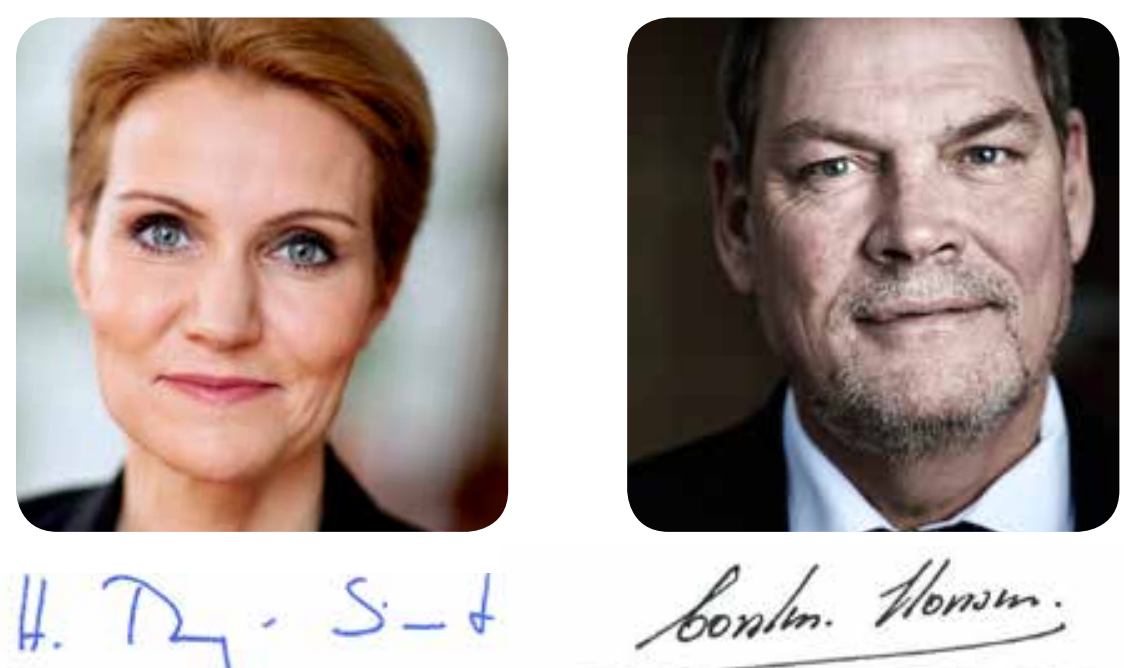

Helle Thorning-Schmidt Prime Minister

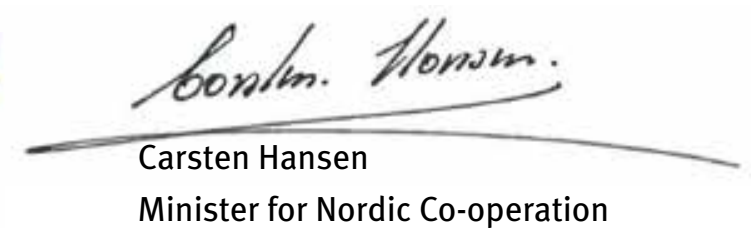



"Together we are stronger." This was the vision expressed by the ministers for Nordic co-operation in 2014 - and it will continue to serve as the guiding light for the Danish Presidency in 2015.

We believe that working together makes a difference when it addresses tangible issues of direct significance to ordinary people, when it delivers initiatives with visible and quantifiable impact, and when it focuses on areas of clear Nordic synergy. Our ambition is to continue to pursue these goals during the Danish Presidency.

We will do it in a distinctly Nordic manner. We will uphold the proud tradition of popular support for our partnership, involving the grassroots in our activities wherever possible. We will also tap into the strong Nordic culture of social engagement via membership of associations by encouraging transparency and participation. In particular, children and young people from across the whole Region will be involved in activities designed both to give them a sense of how the Nordic countries work together, as well as to reinforce the sense of community and affinity that lies at the very heart of our partnership.

In a year when both Denmark and Iceland celebrate the centenary of women's suffrage, gender equality will again be a key theme for a whole range of activities. In many areas, women and men, girls and boys do not enjoy equal opportunities - for example, in schools and in the labour market. The Danish Presidency will address this problem.

During the 12 months Denmark holds the Presidency, an important task will be to continue work on many of the long-term activities that characterise our partnership. One example of this will be the ongoing work to renew and reform official Nordic co-operation, as specified in the Secretary General's report "New Nordic Region". Another particularly important example will be the ongoing endeavours to remove barriers to cross-border freedom of movement in all sectors - both the specific barriers that exist in the North Atlantic, and those that make it difficult to work more closely together in particular policy areas, e.g. social affairs and employment. We will also continue to fight social dumping, an area in with a long Nordic tradition of working together and exchanging experiences on migrant labour.

If the Presidency is to generate tangible results, it must focus its efforts. We have selected four topical themes that concern people in the Region: growth, welfare, values and the Blue Arctic. The main emphasis during the Danish Presidency will be on these four themes. 
The global economic crisis was severe. In the Nordic Region, the downturn in economic activity, loss of jobs and widespread pessimism have cast long shadows. In order to resurrect our economies, many difficult decisions had to be made. The signs are that these measures are now bearing fruit, and the crisis finally seems to be loosening its grip on the Region.

As such, the time is now ripe to concentrate on growth and jobs again including within Nordic co-operation. In 2015, we will continue to develop the Region's position as a leader in areas where our strengths are already visible and where Nordic creativity and innovation will lead to faster growth and more jobs. The potential for this is particularly great in the green and creative sectors. In many ways, the Region is already recognised as a pioneer in green and sustainable growth. Other countries often look to us as a source of inspiration when making important decisions on sustainable energy supplies, more effective use of resources, green transition and climate-friendly initiatives.

The UN negotiations on sustainable development and climate change will have a considerable impact in 2015. A range of global sustainability targets are expected to be adopted as part of the UN's post-2015 development agenda and as follow-up on the Rio+20 conference on sustainable development. The UN climate conference COP21 in Paris will hopefully culminate in a new global climate agreement. By working closely together, the Nordic countries will seek to both exert heavy influence on the negotiations and make our mark on the outcomes.

An example of this will be the work done on our Nordic towns and cities. Urban areas house a growing proportion of the world's population and economic activity. By 2050, $70 \%$ of the global population will live in urban areas. This heavy concentration will put pressure on towns and cities, as a result of which sustainability will be an increasingly important goal for urban development - both in the Nordic Region and elsewhere in the world.

Innovative solutions and planning will be required to build cities that reduce pollution, use fewer resources and contribute to cutting greenhouse-gas emissions, yet remain attractive places to live and provide a setting for a good quality of urban life. Some fascinating Nordic initiatives are already in place, combining architecture and planning with energy efficiency, noise reduction, waste treatment, traffic calming, wellbeing, etc. If we succeed in refining and promoting solutions like these - in the Nordic Region and beyond - everybody who lives in urban areas will benefit in terms of growth, health, employment and quality of life. We want Nordic cities to serve as sustainable engines of growth. 


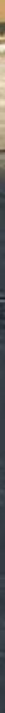


Nordic fashion and design are two other areas in which we already enjoy international renown. Nordic fashion is associated with purity, ethics and minimalism. These are unique positions of strength in an industry that is generally considered extremely resource-heavy and which uses significant amounts of energy, water, chemicals and pesticides. This position of Nordic strength has opened up a number of valuable opportunities at a time when the industry as a whole is under increasing pressure to use resources more effectively, recycle to a greater extent and use fewer chemicals. Decisive steps in this area will make the Region synonymous with a green transition - and boost the already significant growth and jobs potential in the fashion and textile industry.

The Nordic Region has also had positive experiences of using biological products in an effective manner to limit waste and boost profits. Known as the bio-economic approach, this takes into consideration social and environmental interests while boosting competition and providing support to growth industries. The North Atlantic, in particular, offers significant business potential in terms of developing better and more environmentally friendly ways to use biological resources. Making the most of this potential requires a joint Nordic approach in which public-sector bodies and business stakeholders work together to come up with new solutions.

We will:

- launch a project under the heading "Nordic Built Cities" that brings together the most visionary Nordic stakeholders in sectors such as urban planning, architecture, construction, the environment, energy, transport, IT (smart cities), security and wellbeing, in a partnership aimed at making our cities attractive and sustainable

- $\quad$ promote the adoption and implementation of an action plan under the auspices of the environment ministers, and host an event in 2015 both of which will aim to promote the effective use of resources and sustainable Nordic fashion and textile production

- launch a project that involves relevant public-sector bodies and parts of the business sector working together to map out the challenges and opportunities for sustainable growth based on effective use of marine resources in the North Atlantic. 
Over the years, the nations in the Region have built up strong welfare systems that benefit individual citizens and form an integral part of our social model. In many ways, the welfare state is a fundamental part of our Nordic DNA. However, the welfare state cannot remain static - it must evolve over time. A deep economic crisis, like the one we have recently experienced, poses challenges to social cohesion and underlines the need for new, up-to-date solutions in order for the Nordic welfare model remain a strong component of our society.

We have strong foundations upon which to build. The Region possesses wide-ranging knowledge and experience of welfare solutions, as well as unique resources in both the public and private sectors. These competences and knowledge are in demand far beyond the confines of the Region itself. However, the national economies in the Region are small, and access to research, new methods and other initiatives is not unlimited. This clearly indicates that there is potential for closer collaboration on welfare, via partnerships in which we all bring our knowledge and experience to the table under Nordic auspices. This will be a significant element of the Danish Presidency. In key social areas, we will prioritise knowledge acquisition, hone knowledge transfer and work together on new and innovative welfare solutions. This will entail providing practitioners - pre-school teachers, teachers, doctors, nurses, care-home staff working with elderly people, etc. - with access to the best research-based knowledge available and training them to provide the best services imaginable.

This is the case in the health sector, where the Nordic health ministers agreed in Troms $\emptyset$ in 2012, for example, to work more closely together to improve health systems throughout the Region. This decision will now be implemented in a number of specific areas.

Working closer together to share knowledge of the sources of inequality and effective ways of solving this problem will also have an impact on our endeavours to reduce the inequality still found in terms of health and wellbeing. Inequality begins at birth, as witnessed by the fact that fewer children of parents with a short-cycle education attend medical examinations, for example, or are vaccinated. Other factors such as smoking, alcohol, diet and exercise also have an impact on health inequality. The Danish Presidency will pay greater attention to this problem.

Inequality in the labour market will also be addressed via ongoing efforts to combat social dumping. Discussions about this issue in Nordic circles regularly result in positive outcomes, with the countries deriving mutual inspiration from each other's national solutions. The Danish Presidency will 


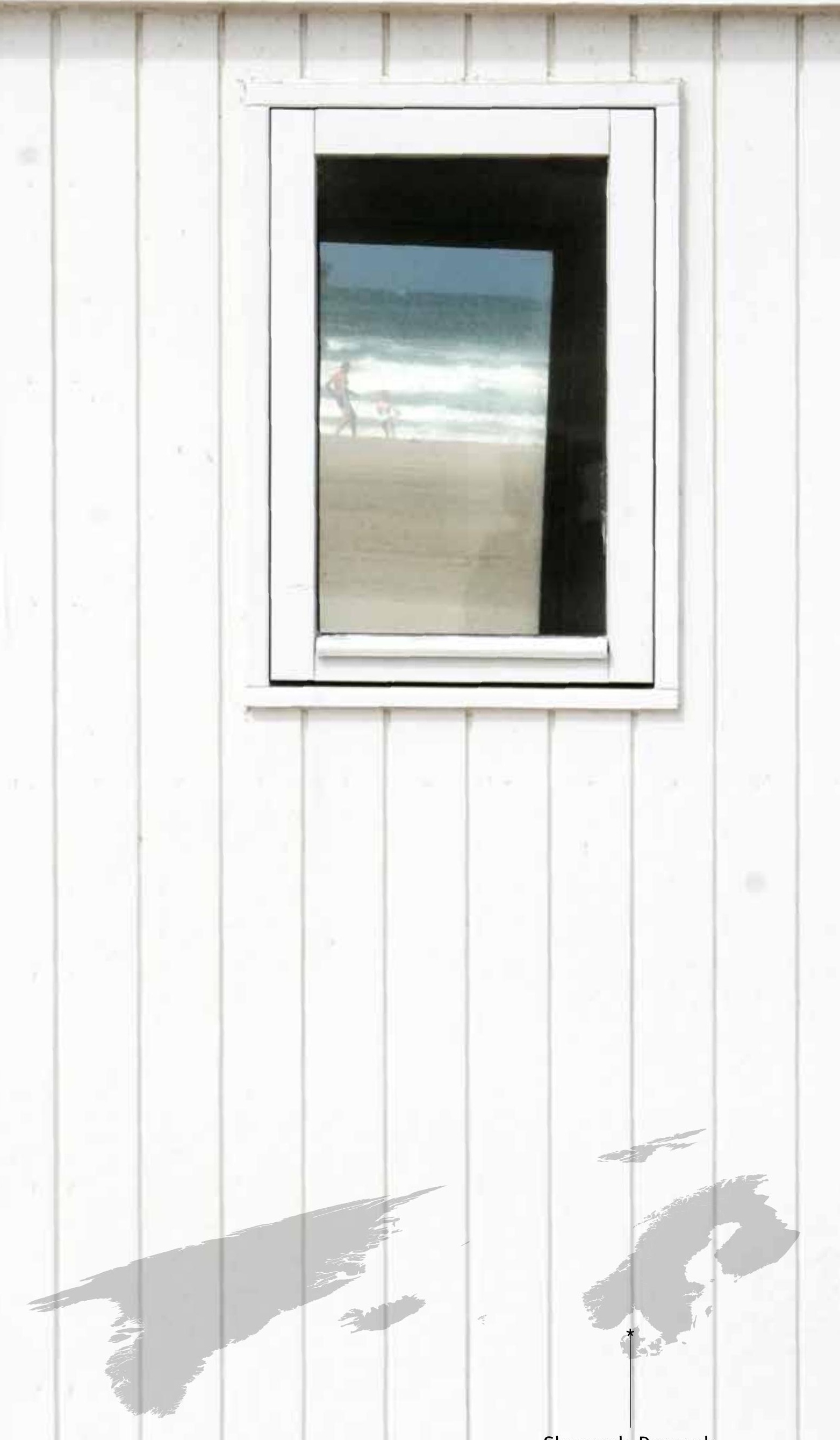

Skagerrak, Denmark 
improve practice by encouraging the exchange of knowledge and experience of national measures and by discussing development trends and joint Nordic interests in relation to EU law.

We will do the same in our work for children and young people, by striving to ensure the best possible teaching and pedagogic practice. This will also help lessen the impact of negative social inheritance on academic results. In addition, we intend to focus on guaranteeing young people the education and training needed in order to gain an initial foothold in the job market and then remain in work. While education and training for young people have to reflect business needs to a greater extent, business must likewise create jobs and training places for young people. Our focus will be on moving youngsters off passive benefits. Nobody will be left behind, and those unable to cope on their own will be given a helping hand to find the right education and training or a job.

One of the challenges facing all of the Nordic countries concerns children in care. They consistently fare less well than their contemporaries in terms of schooling, youth education, and physical and mental health. A holistic view is needed of the whole issue of children in care. At present, we fall short when it comes to breaking the cycle of negative social inheritance. Across the Nordic countries, experience shows that children and young people who face social deprivation - especially boys - still achieve poorer results at school. This has a detrimental effect on their long-term prospects. This is an issue we must focus on.

We will also look at digital solutions - another area in which the Nordic Region is already strong. Digital solutions currently make a tangible difference in a number of key welfare areas that concern ordinary people: telemedicine, rehabilitation programmes and distance learning, for example, all help to make life easier. Promoting business development and innovative digital solutions will make an important contribution to the ongoing evolution of our welfare systems. It will also make the Nordic Region a digital pioneer, and allow us to make the most of the many opportunities in this field. 
We will:

- improve knowledge sharing about initiatives that help reduce inequality in health, e.g. structural measures (new legislation) and making optimum use of past experiences by tailoring prevention, detection, treatment and rehabilitation work to different needs, etc.

- follow up on the recommendations in the report about the future of Nordic co-operation in health (the Könberg Report)

- focus on challenges and initiatives in relation to getting young people into long-term employment

- build upon, and improve, knowledge about food and ensure that it is used to improve food safety, promote healthy diets, prevent destructive animal diseases and develop forms of production that generate growth on a sustainable basis

- follow up on the 2012 "One Health" conference on resistance to antibiotics

- encourage dialogue about combating social dumping in the Nordic Region

- work together to ensure that children and young people in care are guaranteed the best possible opportunities for wellbeing, education, training and jobs. This will be done by sharing the most effective methods and by working together in areas where there is currently a lack of knowledge.

- establish a Nordic forum for work on systematic knowledge about good teaching and pedagogic practices. This project will pave the way for better teaching and pedagogic practice, which will boost academic performance and reduce the impact of negative social inheritance.

- take initiatives to support digital companies' use of open-access data and their opportunities to involve ordinary citizens in trial runs of digital solutions in the various Nordic countries

- help establish a Nordic network and facilitate the sharing of experiences regarding rehabilitation programmes for senior citizens, etc.

- set up a Nordic network to look at the long-term effects of sexual assault and map out the Nordic situation. 
Sustainable growth, innovation, climate and the environment, renewable energy, education, democracy, transparency, low levels of corruption and relative gender equality. These are just some of the characteristics that the rest of the world associates with the Region, and all of them stem from a set of fundamental Nordic values. In the wake of the financial crisis, there is an increasing tendency for a range of countries to turn to us as a source of inspiration for solutions to some of their own social challenges. For example, Nordic education institutions run programmes in welfare-related subjects that encompass a range of similarities and areas of expertise in all of our nations. These have export potential and are a good way of branding our welfare solutions. We can make better use of this interest by focusing even more sharply on the aspects of the Nordic model that can inspire or be applied to other countries and regions. This curiosity about all things Nordic is also reflected in an interest in our culture and food.

We need to attract even more positive international attention and make the most of it. We will make greater use of the Nordic "brand" to promote knowledge of the Region's strengths and core values. There is unexploited potential for more strategic and systematic promotion of the Nordic brand, especially in markets where knowledge of the Region is greater than knowledge of individual countries.

The Danish Presidency will introduce long-term measures to focus strategically on the international branding of the Region. This will be done in accordance with the Council of Ministers' Strategy for the international branding of the Nordic Region, which highlights selected areas.

One example of this will be cultural promotions. In 2013, a major joint promotion was staged in Washington DC under the name "Nordic Cool". Its huge success served to underline the considerable international attention currently being paid to Nordic art and culture. "Nordic Cool" cannot be exported directly to other countries, but it does help underline the potential inherent in increasing knowledge of the Region via ambitious, culturally driven projects. We need to build on this experience and gain even wider exposure for our culture - as a bearer of our values - in the years to come.

The focus in recent years on New Nordic Food has brought about meaningful and significant changes in food culture in a number of the Nordic countries. The trend also underlines some of our basic values: sustainability, creativity, quality and purity. New Nordic Food is also followed with great interest abroad, and there is significant potential in branding the Region as a worldclass food destination. 
The Atlantic Ocean,

the Faroe Islands
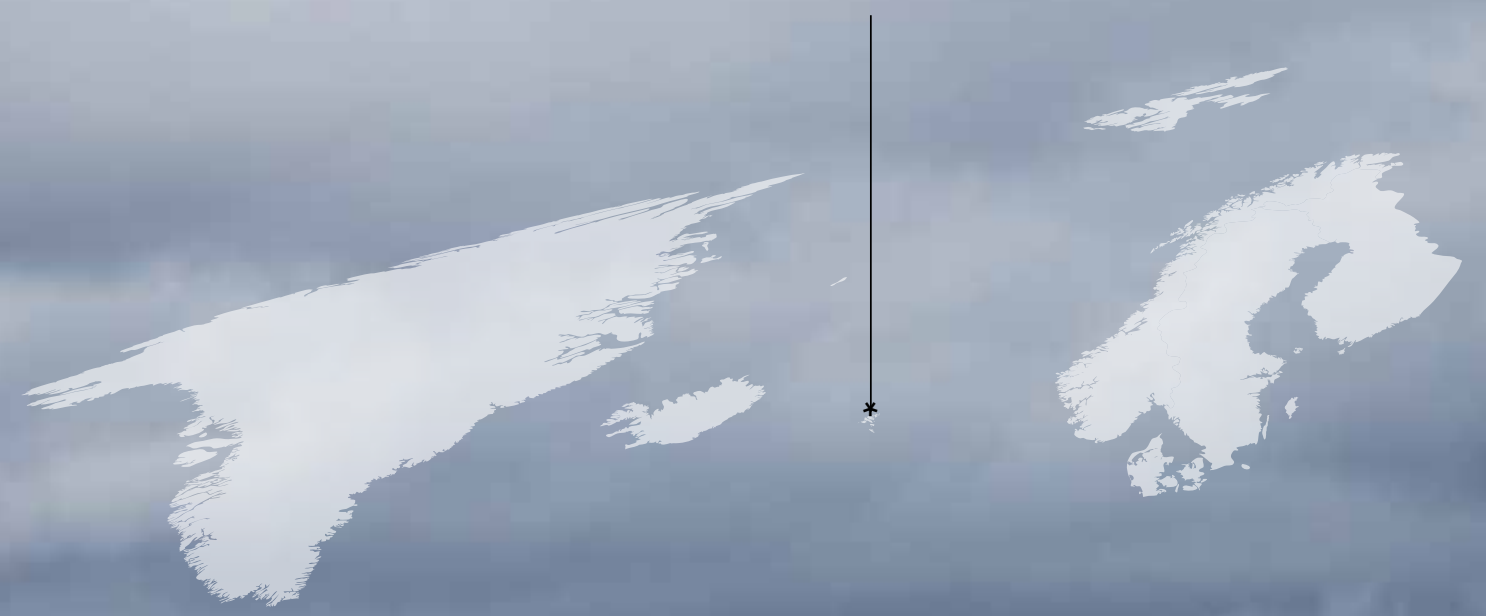
Using the fact that our food is safe, healthy, high quality and stems from sustainable production systems as our basis, we will aim to make the most of this international attention and interest, and disseminate information about Nordic gastronomy not only in the Region, but globally.

The tourism industry is also closely associated with the Nordic brand. To a great extent, its success is linked to knowledge of the Region and its values, and the industry's everyday promotional work helps to spread knowledge of the Region. There is potential for a joint Nordic approach to tourism that will attract even greater attention to the Nordic brand and position the Region as an innovative tourist destination. This can also be combined with targeted efforts in other sectors, such as culture, food, architecture and design. We will make use of these opportunities, for example, to attract tourists from the new growth economies. 
We will:

- set up a working party in 2015 to define a well-structured concept for "Nordic Cool" and outline the organisational framework for future cultural promotions abroad. We will also explore the opportunities for a new "Nordic Cool" event.

- actively use Nordic food to "brand" the Region. We will do this by hosting an annual food festival attended by key figures in Nordic gastronomy and food development. We will also launch an initiative "New Nordic Ultra" - to attract attention to the best raw ingredients from the Far North.

- begin to establish an organisational framework for Nordic approaches to the promotion of tourism, exports, culture and investment, under the working title "Team Norden". As a first step, we will test the development of new initiatives for attracting tourists from growing economies and distant parts of the world - in the first instance, China.

- launch a joint initiative to improve knowledge of, and encourage the export of, Nordic higher education programmes in welfare subjects

- initiate a study of the opportunities for working more closely together in architecture and design in international contexts

- set up a financial and analytical platform for the international branding of the Region and the Nordic model. We will achieve this by holding a conference in $\mathbf{2 0 1 5}$ for the leading researchers in the field. Afterwards, they will submit a series of policy recommendations concerning the strengths and weaknesses of the model and its usefulness in other countries and regions. 
Climate changes have triggered a transformation of the Arctic - a trend that will only accelerate in years to come. From the polar area, over the North Atlantic to Northern Europe, climate change will have a profound affect on both the challenges faced by local populations and the opportunities available to them. Dealing with this new situation will be a major task for the Arctic societies.

The Nordic Region will play a proactive part in efforts to guarantee sustainable development based on the needs of the local people. In doing so, we will draw on the Region's long-standing tradition of collaboration and knowledge sharing across a number of sectors, e.g. the environment, climate, energy, sustainable development, research, culture and gender equality.

Experience of this Nordic multi-sectoral approach will be used to supplement and underpin work in the Arctic - especially in the Arctic Council, which is the primary forum for discussion in and about the Arctic region.

Under the working title "The Blue Arctic", the Danish Presidency will focus on areas in which the Arctic and the Nordic Region have something to gain by working together. This work will revolve around the "Blue" aspect because the sea will play a crucial role in the transformation of the Arctic. The sea is essential to nature, culture, business development and transport. Climate change will only make it even more important to adopt a holistic approach to the management of "blue natural resources". Indigenous peoples and other users of the sea possess valuable insight into marine life.

Climate change means melting ice, new shipping routes and heavier maritime traffic in the Arctic. This may lead to growth and jobs in both the Nordic Region and the Arctic. Great interest has already been expressed, and stakeholders from the Arctic and beyond are ready to make the most of these opportunities. This will entail a need to support business development in the region, and, crucially, special measures to improve safety at sea. It is also critical that high environmental and safety standards are maintained, so that the environment is protected even as the level of activity rises.

The expected rise in maritime activity will bring new pressure to bear on the marine environment. Protection of marine biodiversity will become increasingly important. It is expected that there will be a need to study how the Arctic marine environment reacts to increased levels of maritime transport and fishing. Properly documented scientific knowledge about the biodiversity of the seabed is essential for future fisheries and environmental management, as well as for commercial fishing. The Nordic countries will be able to transfer knowledge and experience gained in the Arctic to other marine environments and enhance knowledge of Nordic waters in general. 


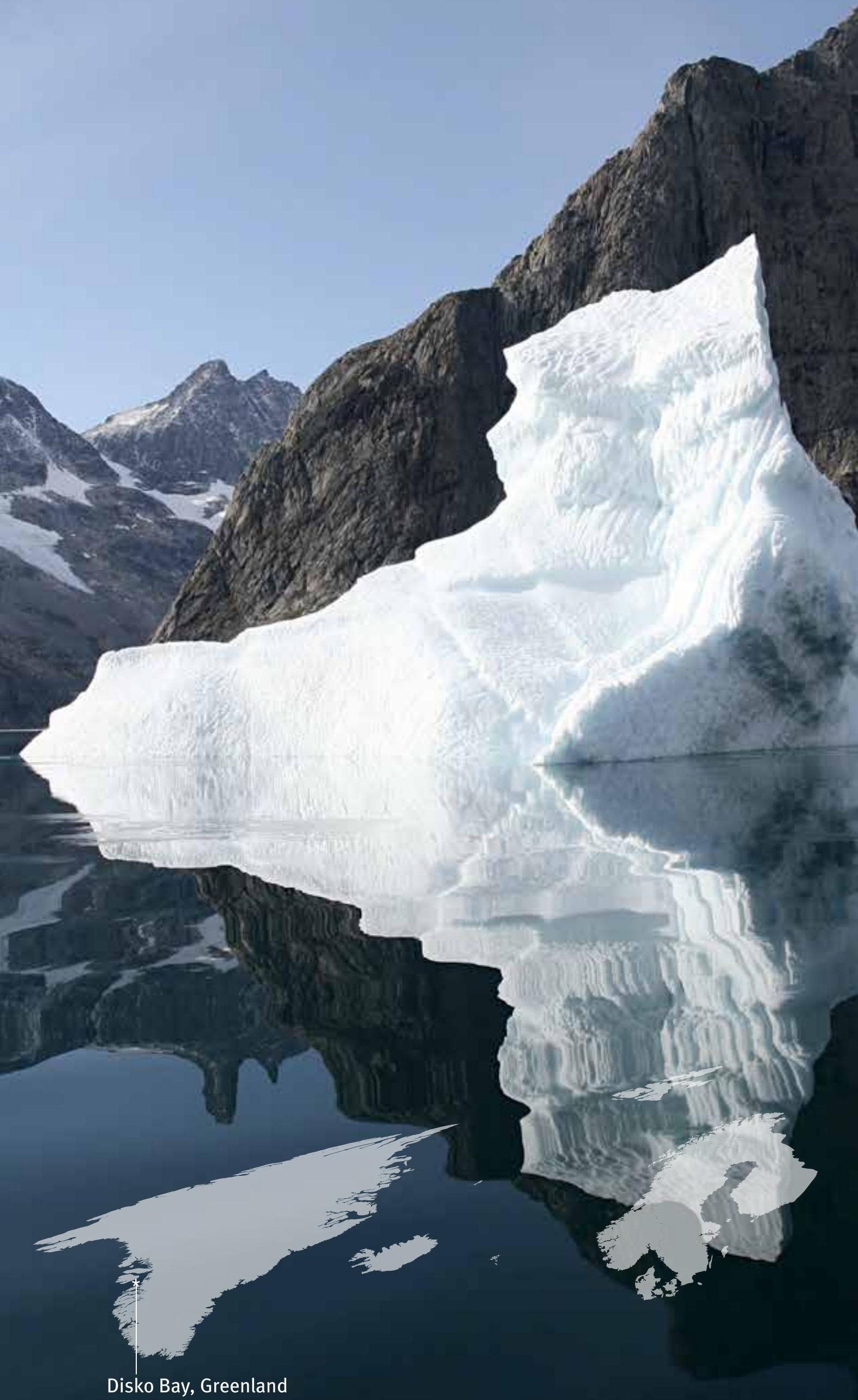


We will:

- support safety at sea in the Arctic via a project to further refine the e-navigation tool "ArcticWeb", which provides an overview of ships in the Arctic, and by developing a joint Arctic maritime web portal with relevant and necessary information about shipping in the area

- create a platform for knowledge sharing and development of a joint Nordic protocol for mapping and monitoring the biodiversity and vulnerability of the sea bed

- follow up on the Nordic Council of Ministers' new Arctic co-operation programme for 2015-17 and promote closer Nordic dialogue about multi-sectoral Arctic themes

- supplement the work on Arctic questions in other forums, especially the Arctic Council. 
The Atlantic Ocean, Iceland

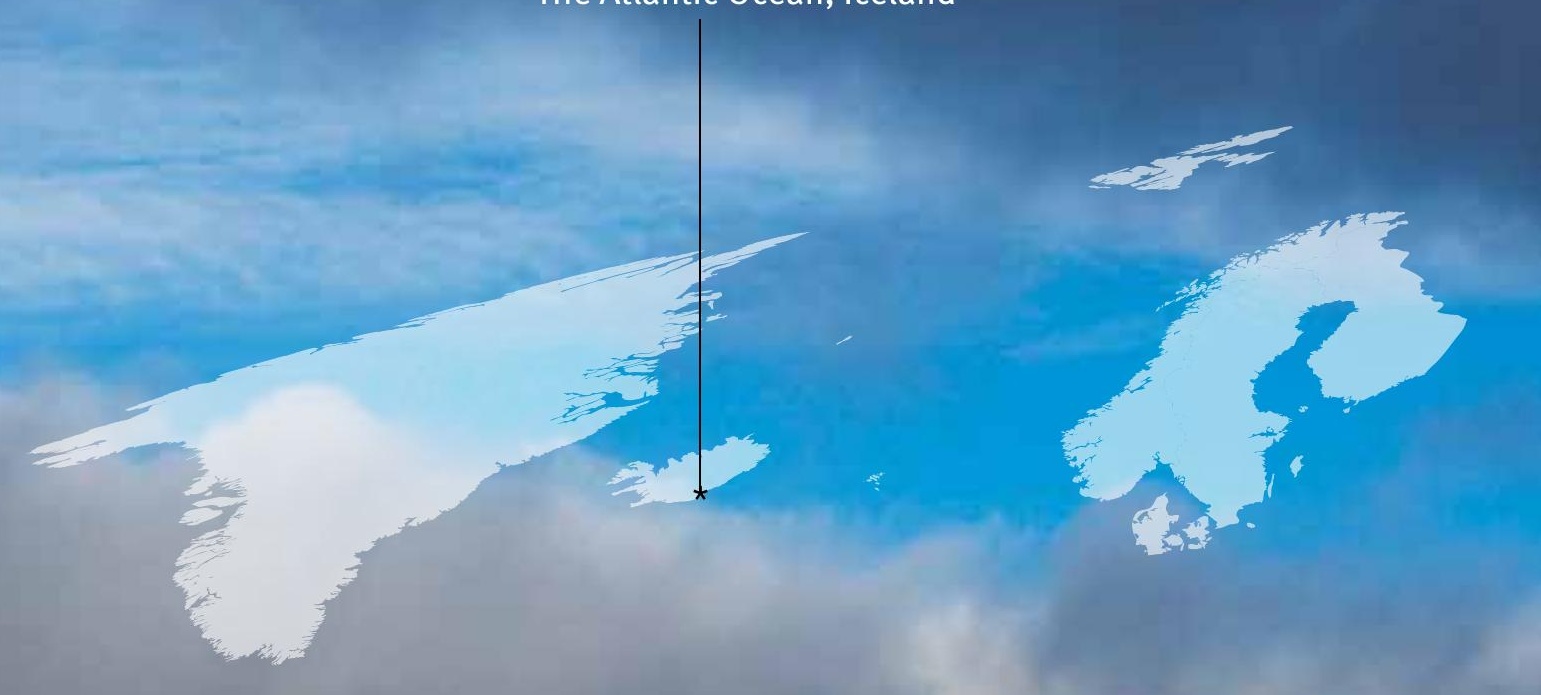



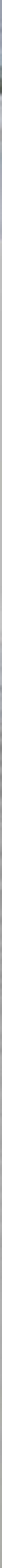

Lofoten, the Norwegian Sea, Norway 


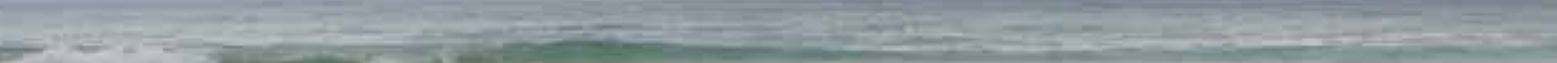

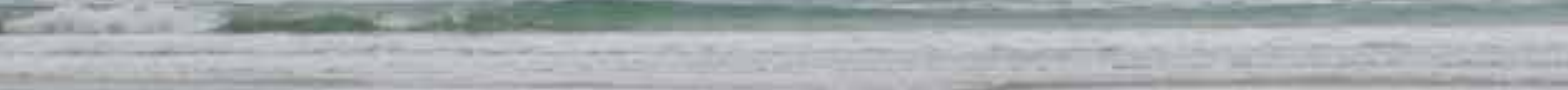

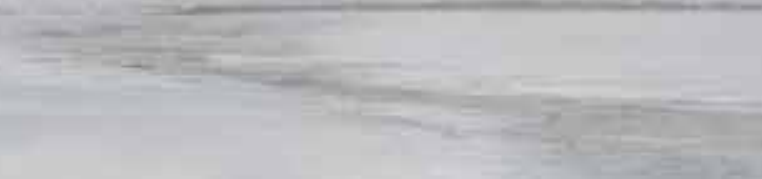

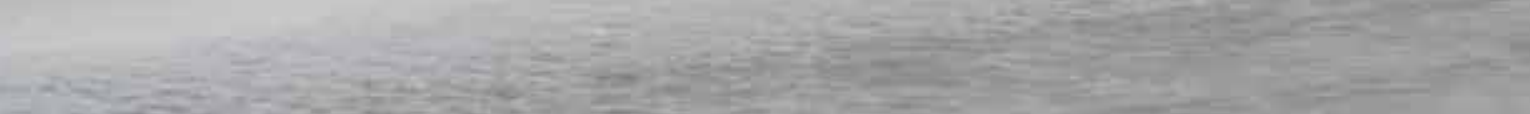
I

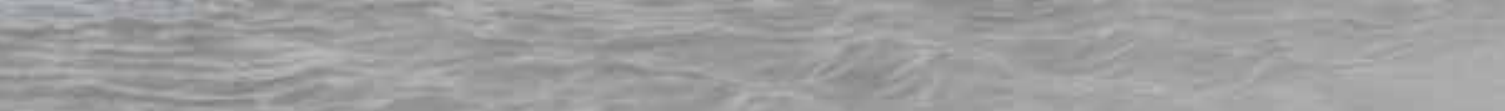

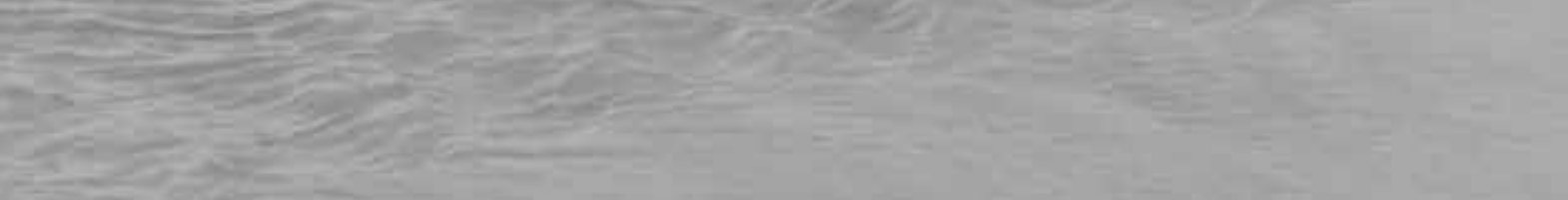

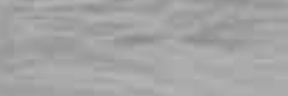

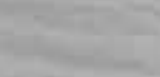


Nordic Council of Ministers

Ved Stranden 18

DK-1061 Copenhagen K

www.norden.org

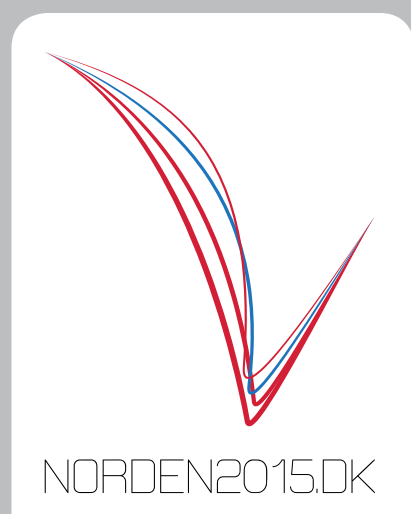

Further information on the Danish Presidency of the Nordic Council of Ministers is available at www.norden2015.dk

\section{Ministry of Foreign Affairs}

\section{Secretariat for}

\section{Nordic Co-operation} norden2015@um.dk

Asiatisk Plads 2 DK-1448 Copenhagen Denmark

Phone: +45 33920000

\section{ANP 2014:747}

ISBN 978-92-893-3786-1 (PRINT) ISBN 978-92-893-3807-3 (PDF) 